\title{
Prognostic value of preoperative computed tomography in HBV-related hepatocellular carcinoma patients after curative resection
}

This article was published in the following Dove Press journal: OncoTargets and Therapy

\author{
Wei Zhang ${ }^{1, *}$ \\ Jie Chen ${ }^{2, *}$ \\ Lijuan Liu' \\ Lili Wang' \\ Junjie Liu' \\ Danke Su' \\ 'Department of Radiology; ${ }^{2}$ Department \\ of Hepatobiliary Surgery, Affiliated Tumor \\ Hospital of Guangxi Medical University, \\ Nanning, Guangxi Zhuang Autonomous \\ Region, People's Republic of China \\ *These authors contributed equally to \\ this work
}

Correspondence: Danke Su

Radiology Department, Affiliated Tumor Hospital of Guangxi Medical University,

7I Hedi Road, Nanning, Guangxi Zhuang

Autonomous Region, People's Republic of

China

Tel +860 77l 53I 6832

Email sudanke33@sina.com
Background: Preoperative treatments are considered for patients with worse outcome to improve overall survival and reduce tumor relapse. This study developed a prognostic risk estimation for patients with hepatitis B virus (HBV)-related solitary hepatocellular carcinoma after curative resection, including preoperative computed tomography (CT) signatures.

Methods: Preoperative multiphasic CTs for 166 patients with operable HCC were performed in our hospital from 15 November 2013 through 15 May 2015. Follow-up information, until 5 June 2017, included: CT, pathological and clinical characteristics, and recurrence and metastases of HCC confirmed by pathological or radiological diagnosis. The parameters were analyzed by the Kaplan-Meier method and Cox proportional hazards regression analysis.

Results: In multivariate analyses, overall survival was not significantly associated with any of the analyzed prognostic risk factors, but did show that the following were significant prognostic risk factors for disease-free survival: larger tumor size, positive radiogenomic venous invasion, non-smooth tumor margin, and histological microvascular invasion. These were all incorporated into the nomogram. The calibration curves for predicting the probability of disease-free survival between the nomogram and actual observation showed good conformity.

Conclusion: In patients with HBV-related HCC, CT signatures were a noninvasive significant indicator of disease-free survival. Thus, consideration of CT signatures may optimize preoperative treatment strategies for the individual patient.

Keywords: hepatocellular carcinoma, computed tomography, nomogram, prognosis

\section{Introduction}

Hepatocellular carcinoma (HCC) is the third most common cause of cancer-related death in the world. ${ }^{1}$ In 2012 , China alone accounted for $\sim 50 \%$ of new liver cancer cases and deaths worldwide, ${ }^{2}$ with 5 -year survival rates only reaching $10.1 \%{ }^{3}$

$\mathrm{HCC}$ is a common pathological type of liver cancer, ${ }^{4}$ and chronic hepatitis B virus (HBV) infection is the most common cause of $\mathrm{HCC}$ in the Chinese population. ${ }^{5}$ In China, the Guangxi Zhuang Autonomous Region has a higher prevalence of HBV infection and aflatoxin B1 exposure compared with other provinces, and subsequently higher morbidity and mortality due to $\mathrm{HCC}^{6-8}$

For patients with solitary HCC, surgical resection is potentially curative. 9 However, prognosis is still not satisfactory, because of high postoperative 
recurrence and metastasis. ${ }^{10-14}$ A major obstacle to choosing better curative procedures is the lack of tools for preoperatively determining the aggressiveness of HCC.

Researchers have attempted different methods for predicting the prognosis of $\mathrm{HCC}$ cohorts. ${ }^{15-19}$ Computed tomography $(\mathrm{CT})$ is a noninvasive imaging modality that is routinely used for diagnosis, treatment planning, and monitoring of liver cancer, CT is the conventional low cost standard modality for diagnosing HCC.

The gene expression patterns in tumor tissue can portend patients' therapeutic response and prognosis ${ }^{20}$ and may be predicted by imaging traits. ${ }^{21}$ For example, moving toward personalized medicine, Segal et $\mathrm{al}^{21}$ reported that a combination of $28 \mathrm{CT}$ imaging traits in HCC could be used to reconstruct $78 \%$ of global HCC gene-expression profiles that reflected patient prognosis. Another study showed that gene-expression profiles of cancer can suggest tumor biological behavior and clinical course, and can be mapped to corresponding tumor-imaging signatures. ${ }^{22}$ An imaging feature identified as a powerful prognostic biomarker can provide significant additional information in colorectal cancer. ${ }^{23}$

Similarly, studies have indicated that CT imaging can be used as a significant predictor of early recurrence in HCC after resection (within 1 year), ${ }^{24}$ as well as poor overall survival (OS) in HCC patients after surgical treatment or liver transplantation. ${ }^{25}$ The underlying mechanisms of disease-free survival (DFS) and OS are likely associated with the biological aggressiveness of the tumor. ${ }^{26}$ Yet, it is not known whether CT signatures may be a biomarker of DFS or OS in HBV-related solitary HCC.

Microvascular invasion (MVI) is an important independent risk factor of recurrence after surgical treatment of HCC. ${ }^{27,28}$ Recent studies suggest that non-smooth tumor margin ${ }^{29-33}$ may be used to predict MVI. However, the mechanism of non-smooth tumor margin that drives MVI remains unclear. One of our previous studies showed that non-smooth tumor margin correlated with postoperative $\mathrm{HCC}$ recurrence. ${ }^{34}$ A subgroup analysis of negative MVI is used to explore possible mechanisms of non-smooth tumor margin.

Recent studies showed that postoperative pathological variables, including histological differentiation, ${ }^{35}$ satellite node of tumor $^{36}$ and liver capsular invasion, ${ }^{37,38}$ were independent indicators of postoperative HCC recurrence. To improve the accuracy of preoperative prediction model, pathological variables would be better to correct the conclusions of preoperative $\mathrm{CT}$ by multivariate analysis. In addition, a postoperative predictive model was established to improve treatment strategies for the patients who had already undergone surgery.

To improve the preoperative surgical planning of patients with HBV-related solitary HCC, this retrospective study investigated the prognostic value of CT signatures. The clinical data, pathological results, and serological results were assessed as secondary endpoints.

\section{Methods}

\section{Patients}

The present study was approved by the Institutional Review Board of Affiliated Tumor Hospital of Guangxi Medical University and written informed consent was obtained from all individuals in this research project. This study initially included 166 patients (135 men and 31 women; aged 24-79 y, mean age 48.0 y) with operable HCC (ie, meeting the Barcelona Clinic Liver Cancer requirements for operability based on imaging), ${ }^{39}$ who underwent preoperative $\mathrm{CT}$ in our hospital from 15 November 2013 through 15 May 2015. The follow-up information was obtained from the medical records of our hospital. All patients signed informed consent forms to undergo $\mathrm{CT}$ and curative resection.

Follow-ups (closed on 5 June 2017) confirmed recurrence and metastases of HCC by pathological or radiological diagnosis. OS was defined as the time from surgery to the date of death or last follow-up. DFS was the time from surgery to the date of recurrence, metastasis, death, or last follow-up.

All patients met the following criteria for inclusion in this study: no cancer-related treatment or biopsy performed on a solitary HCC prior to the CT imaging scan, and preoperative $\mathrm{CT}$ performed $\leq 1$ month before surgery; underwent radical resection, with HCC confirmed by histopathology; without macrovascular invasion or metastasis on preoperative $\mathrm{CT}$ imaging; positive for serum $\mathrm{HBV}$ surface antigen; without hepatitis $\mathrm{C}$ virus (HCV) infection; and Child-Pugh class A, according to the Child-Pugh liver disease classification.

\section{CT imaging protocol}

CT images of the liver were performed on a 64-MDCT scanner (SOMATOM Sensation 64, Siemens, Germany) 
equipped with the following parameters: z-axis modulation; spiral pitch 1; 5-mm section thickness; 2-mm reconstruction gap; field of view $311 \mathrm{~mm} ; 120 \mathrm{kVp}$; $230 \mathrm{~mA}$; and a standard reconstruction algorithm. Nonionic contrast medium (iopromide, $300 \mathrm{mgI} / \mathrm{mL}$ ) was administered at a total dose of $100 \mathrm{~mL}$ with an injection rate of $3 \mathrm{~mL} / \mathrm{s}$. For the hepatic arterial and portal venous phases, scanning began $\sim 30-35$ and $65--$ 70 seconds, respectively, after injection of the contrast medium. Equilibrium phase images were acquired about 180-200 seconds after injection of the contrast medium. The scanning range included the entire liver while the patients held their breath. Coronal and sagittal images were reconstructed with a $5-\mathrm{mm}$ section thickness.

\section{Image evaluation}

The basic imaging traits were the absence or presence of the following: radiologic evidence of liver cirrhosis; according to previous studies, liver cirrhosis could be diagnosed by CT with a sensitivity of $84 \%$, a specificity of $100 \%$, and an accuracy of $94 \% ;{ }^{40}$ splenomegaly; ascites; esophageal and gastric varices; peritumoral enhancement; ${ }^{29}$ necrosis; and radiographic venous invasion (RVI; Figure 1). According to previous studies, ${ }^{24,25}$ RVI was redetermined according to 3 imaging features (defined below): internal vessels, hypodense halo, and tumor-liver difference. Internal vessels are observed as linear vessels enhancement within the tumor on venous phase imaging. A hypodense halo is a rim of hypodensity, partially or completely surrounding the tumor. The tumor-liver difference is a focal or circumferential sharp transition in attenuation between the tumor and the adjacent liver parenchyma without a hypodense halo.

In addition, imaging data of the following tumor characteristics were noted: location (left, right, or both lobes); size (maximal diameter of the largest cross section $<10 \mathrm{~cm}$ or $\geq 10 \mathrm{~cm}$ ); margin (smooth or non-smooth margin; Figure 2), ${ }^{29}$ and capsule (complete, incomplete, or without tumor capsule). ${ }^{29}$

The imaging features of each patient were recorded as the consensus of 2 experienced radiologists (Wei Zhang and Lijuan Liu, with 10 and 6 years of experience in reading liver CTs, respectively). If necessary, a third radiologist joined a consensus conference.

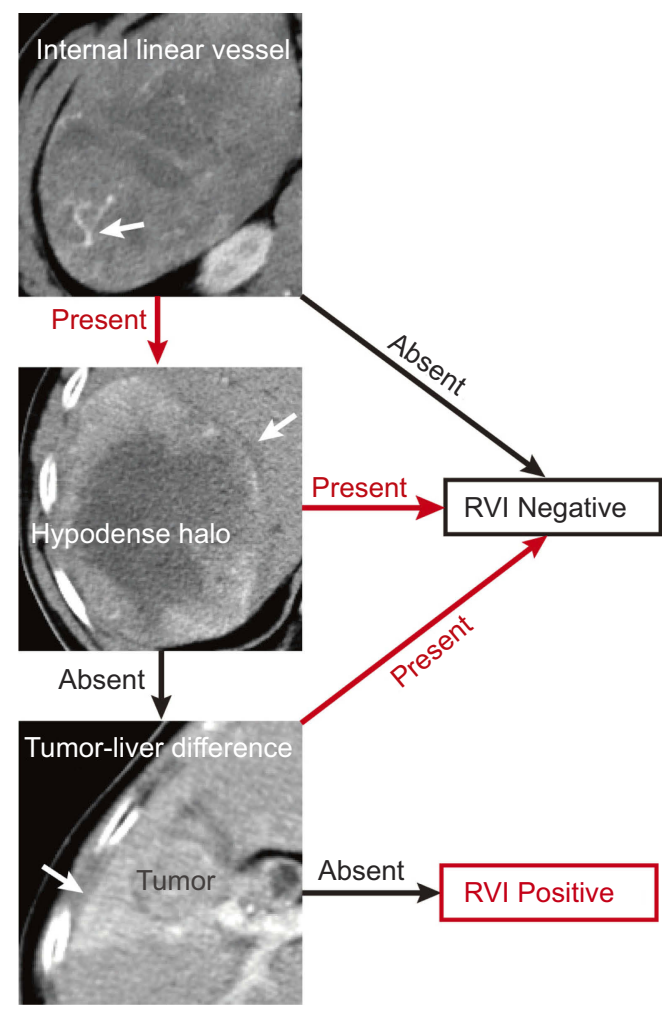

Figure I RVI is determined by 3 traits in patients with HCC.

Abbreviations: HCC, hepatocellular carcinoma; RVI, radiographic venous invasion.

\section{Clinical risk factors}

The following potential demographic and lifestyle risk factors were analyzed: age ( $\leq 60$ or $>60 \mathrm{y})$; gender; ethnicity (Han or minority); body mass index (BMI, $\leq 25$ or $>25$ ); smoking status (none or ever); and drinking status (none or ever). In addition, the presence or absence of the following was analyzed as potential risk factors: satellite node of tumor; MVI; and liver capsular invasion. The clinical risk factors also included: histological differentiation (according to Edmondson-Steiner grading system, Grade I was considered as high differentiated, Grade II/ III as moderate, and Grade IV as poor); alpha-fetoprotein (AFP; $<400$ or $\geq 400 \mathrm{ng} / \mathrm{mL}$ ); ratio of serum albumin to globulin $(\mathrm{A} / \mathrm{G} ; \leq 2.5$ or $>2.5)$; alanine aminotransferase (ALT; $\leq 40$ or $>40 \mathrm{U} / \mathrm{L}$ ); aspartate aminotransferase (AST; $\leq 40$ or $>40 \mathrm{U} / \mathrm{L}$ ); alkaline phosphatase (ALP; $\leq 150$ or $>150 \mathrm{U} / \mathrm{L}$ ); lactate dehydrogenase (LDH; $\leq 285$ or $>285 \mathrm{U} / \mathrm{L}$ ); and $\gamma$-glutamyl transferase (GGT; $\leq 50$ or $>50 \mathrm{U} / \mathrm{L}$ ).

The threshold values chosen for AFP, A/G, ALT, AST, ALP, LDH, and GGT levels were based on the normal ranges used at our institution. 


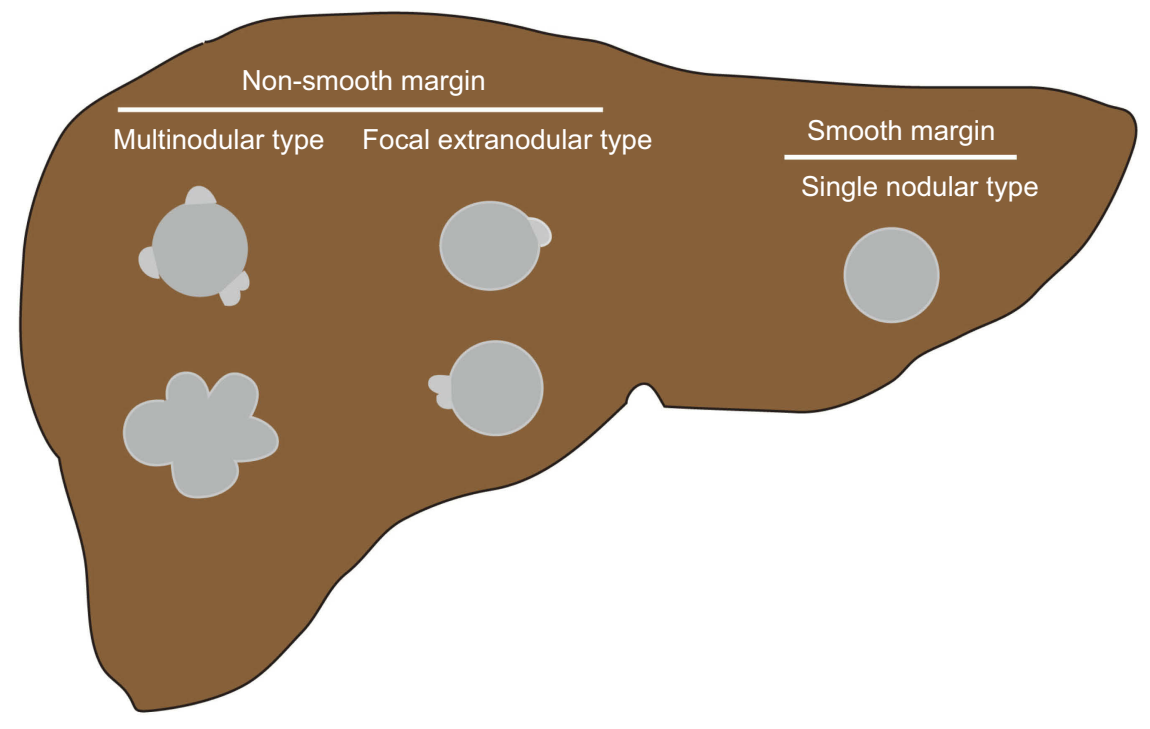

Figure 2 Illustration shows 2 patterns of tumor margins (drawing by Zhang).

\section{Statistical analysis}

Survival analyses were performed using the Kaplan-Meier method with the log-rank test for different CT signatures and clinical risk factors. Cox proportional hazards regression analysis was performed to calculate the crude or adjusted hazard ratio (HR) and $95 \%$ confidence interval (CI) in univariate and multivariate survival analyses, with adjustment for CT signatures, pathological parameters, and serum indicators.

A nomogram was formulated based on the results of multivariate Cox regression analysis and using the Regression Modeling Strategy (rms) in the R software package version 3.4.0 (http://www.r-project.org/). ${ }^{41} \mathrm{~A}$ final nomogram model was based on a backward stepdown selection process using Akaike's information criterion. ${ }^{42}$

A $P$-value $<0.05$ was considered statistically significant. Statistical analyses were performed with SPSS version 16.0 (IBM, Chicago, IL, USA) statistical software.

\section{Results}

\section{Patient characteristics}

A total of 157 patients (131 men and 26 women) with HBV-related HCC completed the follow-up period successfully, with a loss to follow-up rate of $5.4 \%$. Of the 157 patients, 42 patients $(26.8 \%)$ experienced recurrence and metastasis, of whom $10(6.4 \%)$ died from cancer. The 42 cases of recurrence or metastasis consisted specifically of the following: $32(76.2 \%)$ intrahepatic recurrence; $4(9.5 \%)$ extrahepatic metastases ( 2 in the lung, 1 on the peritoneum, and 1 in lymph nodes); and 6 $(14.3 \%)$ with both intrahepatic recurrence and extrahepatic metastases. These cases were treated as follows: 19 repeat curative resection; 6 radiofrequency ablation; 8 transcatheter arterial chemoembolization; 3 sorafenib; 5 transcatheter arterial chemoembolization and sorafenib; and 1 without any treatment. Liver cirrhosis was confirmed by histopathological examination and radiology.

\section{Prognostic risk factors for OS and DFS}

The univariate analysis indicated that liver capsular invasion and larger tumor size were significantly associated with poor OS (Table 1). However, in the multivariate analysis, it was found that the analyzed prognostic risk factors were not significantly associated with OS.

In the 157 patients followed for $>2$ years, the univariate analysis indicated that the significant prognostic factors of worse DFS were the following (Table 2; Figure 3): larger tumor size; positive RVI; non-smooth tumor margin; and positive MVI.

The following were not significant prognostic factors (Table 2): age; gender; ethnicity; BMI; smoking or drinking status; radiologic evidence of liver cirrhosis; splenomegaly; ascites; esophageal and gastric varices; tumor location; peritumoral enhancement; necrosis; tumor capsule incomplete or without tumor capsule; moderate or poor tumor differentiation; satellite node of tumor; capsular invasion of the liver; or elevated AFP, A/G, ALT, AST, ALP, LDH, and GGT levels. 
Table I Univariate and multivariate analyses of preoperative factors associated with overall survival

\begin{tabular}{|c|c|c|c|c|c|c|}
\hline & & & $\mathbf{P t}, \mathbf{n}$ & Events, $n$ & Univariate & Multivariate \\
\hline & & & & & Log-rank $P$ & Log-rank $P$ \\
\hline Clinical characteristics & $\begin{array}{l}\text { Age, y } \\
\text { Gender } \\
\text { Ethnicity } \\
\text { BMI } \\
\text { Smoking status } \\
\text { Drinking status }\end{array}$ & $\begin{array}{l}\leq 60 \\
>60 \\
\text { Male } \\
\text { Female } \\
\text { Han } \\
\text { Minority } \\
\leq 25 \\
>25 \\
\text { None } \\
\text { Ever } \\
\text { None } \\
\text { Ever }\end{array}$ & $\begin{array}{l}141 \\
16 \\
131 \\
26 \\
83 \\
74 \\
116 \\
41 \\
111 \\
46 \\
110 \\
47\end{array}$ & $\begin{array}{l}9 \\
1 \\
7 \\
3 \\
4 \\
6 \\
9 \\
1 \\
9 \\
1 \\
9 \\
1\end{array}$ & $\begin{array}{l}0.978 \\
0.255 \\
0.390 \\
0.237 \\
0.165 \\
0.161\end{array}$ & \\
\hline CT signatures & $\begin{array}{l}\text { Cirrhosis } \\
\text { Splenomegaly } \\
\text { Ascites } \\
\text { Positions } \\
\text { Tumor size, cm } \\
\text { Peritumoral enhancement } \\
\text { Necrosis } \\
\text { RVI } \\
\text { Tumor margin } \\
\text { Radiological capsule } \\
\text { Esophageal, gastric varices }\end{array}$ & $\begin{array}{l}\text { Absent } \\
\text { Present } \\
\text { Absent } \\
\text { Present } \\
\text { Absent } \\
\text { Present } \\
\text { Left lobe } \\
\text { Right lobe } \\
\text { Both } \\
<10 \\
\geq 10 \\
\text { Absent } \\
\text { Present } \\
\text { Absent } \\
\text { Present } \\
\text { Absent } \\
\text { Present } \\
\text { Smooth } \\
\text { Non-smooth } \\
\text { Complete } \\
\text { Incomplete } \\
\text { Absent } \\
\text { Absent } \\
\text { Present }\end{array}$ & $\begin{array}{l}37 \\
120 \\
69 \\
88 \\
146 \\
11 \\
38 \\
110 \\
9 \\
142 \\
15 \\
142 \\
15 \\
63 \\
94 \\
121 \\
36 \\
99 \\
58 \\
75 \\
50 \\
32 \\
141 \\
16\end{array}$ & $\begin{array}{l}2 \\
8 \\
5 \\
5 \\
9 \\
1 \\
2 \\
7 \\
1 \\
6 \\
4 \\
10 \\
0 \\
3 \\
7 \\
7 \\
3 \\
4 \\
6 \\
4 \\
5 \\
1 \\
8 \\
2\end{array}$ & $\begin{array}{l}0.780 \\
0.690 \\
0.787 \\
0.808 \\
0.000 \\
0.294 \\
0.496 \\
0.540 \\
0.105 \\
0.435 \\
0.340\end{array}$ & $\begin{array}{l}0.887 \\
0.176 \\
0.154 \\
0.292 \\
0.143 \\
0.169 \\
0.186 \\
0.129 \\
0.128 \\
0.326 \\
0.142\end{array}$ \\
\hline Pathological evidence & $\begin{array}{l}\text { Histological differentiation } \\
\text { Satellite node } \\
\text { MVI } \\
\text { Liver capsular invasion }\end{array}$ & $\begin{array}{l}\text { Well } \\
\text { Moderate } \\
\text { Poor } \\
\text { Absent } \\
\text { Present } \\
\text { Absent } \\
\text { Present } \\
\text { Absent } \\
\text { Present }\end{array}$ & $\begin{array}{l}11 \\
75 \\
71 \\
143 \\
14 \\
102 \\
55 \\
81 \\
76\end{array}$ & $\begin{array}{l}0 \\
3 \\
7 \\
10 \\
0 \\
4 \\
6 \\
2 \\
8\end{array}$ & $\begin{array}{l}0.235 \\
0.320 \\
0.074 \\
0.040\end{array}$ & $\begin{array}{l}0.583 \\
0.587 \\
0.127 \\
0.117\end{array}$ \\
\hline Serum parameters & $\begin{array}{l}\text { AFP, ng/mL } \\
\text { A/G }\end{array}$ & $\begin{array}{l}<400 \\
\geq 400 \\
\leq 2.5\end{array}$ & $\begin{array}{l}97 \\
60 \\
148\end{array}$ & $\begin{array}{l}4 \\
6 \\
9\end{array}$ & $\begin{array}{l}0.139 \\
0.449\end{array}$ & $\begin{array}{l}0.134 \\
0.378\end{array}$ \\
\hline
\end{tabular}

(Continued) 
Table I (Continued).

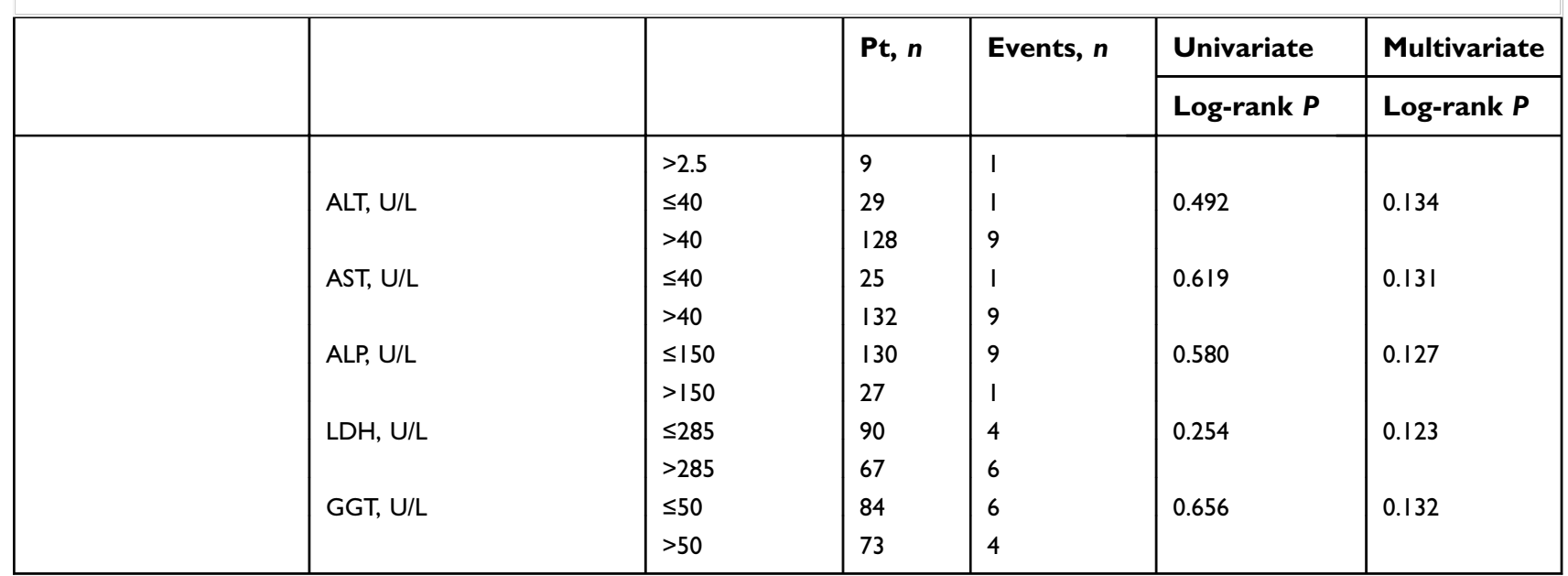

Abbreviations: $\mathrm{CT}$, computed tomography; RVI, radiographic venous invasion; MVI, microvascular invasion; Pt, patient; AFP, alpha-fetoprotein; A/G, serum albumin to globulin; ALT, alanine aminotransferase; ALP, alkaline phosphatase; LDH, lactate dehydrogenase; GGT, $\gamma$-glutamyl transferase.

After adjusting for risk factors in the Cox proportional hazards regression analysis, the following were significant prognostic risk factors of DFS (Table 3): larger tumor size; positive RVI; non-smooth tumor margin; or positive MVI. RVI and MVI were analyzed separately because of collinearity between RVI and MVI.

The following were not significantly associated with DFS (Table 3): radiologic evidence of liver cirrhosis; splenomegaly; ascites; esophageal or gastric varices; tumor location; peritumoral enhancement; necrosis; tumor capsule incomplete or without tumor capsule; pathological parameters except for MVI; and elevated serum levels of parameters.

\section{DFS of RVI, non-smooth tumor margin and tumor size in stratified analyses}

With positive MVI, a positive RVI (HR 0.578 ; 95\% CI 0.156-2.137; $P=0.411$ ), and non-smooth tumor margin (HR 2.103; 95\% CI 0.424-10.430; $P=0.363$ ) were not associated with worse DFS in these HBV-related HCC patients.

With negative MVI, a positive RVI (HR, 12.750; 95\% CI: $2.182-74.492 ; P=0.005)$ and non-smooth tumor margin (HR, 18.188; $P=0.001$; 95\% CI: 3.320-99.630) were associated with poor DFS.

In stratified analyses, larger tumor size in negative MVI (HR, 2.361; $P=0.173$; 95\% CI: $0.687-8.114$ ) and in positive MVI (HR, 2.491; $P=0.100$; 95\% CI: $0.840-7.387$ ) were not associated with worse DFS in these HBV-related HCC patients.

\section{Prognostic nomogram for DFS and validation}

A prognostic nomogram of the preoperative CT based on the Cox regression model for DFS in the primary cohort was constructed (Figure 4A). The C-index for DFS prediction was 0.698 (95\% CI: $0.655-0.741)$. Bootstrapping validation suggested the suitability of the prognostic model for patients with operable HCC. The calibration plot for predicting the probability of DFS at 1-, 2-, or 3-years after curative resection showed good conformity between the nomogram and the actual observation (Figure 4B-D).

A prognostic nomogram that integrated all significant independent risk factors for DFS in the primary cohort was also constructed (Figure 5A). The nomogram predicts the probability that the patient will develop recurrence or metastasis within 1-, 2-, or 3-years after curative resection. The $\mathrm{C}$-index for DFS prediction was 0.728 (95\% CI: $0.641-0.815)$. The nomogram was validated internally using bootstrapping. The model showed good validation (Figure 5B-D).

\section{Discussion}

In the present study, we investigated the ability of CT image characteristics to predict the prognosis of HBVrelated HCC after curative resection. Preoperative multiphasic CTs of patients with operable HCC were analyzed, as well as pathology and clinical characteristics, and recurrence and metastases of HCC at follow-up. The univariate and multivariate analyses showed that 
Table 2 Univariate analysis of preoperative factors associated with disease-free survival

\begin{tabular}{|c|c|c|c|c|c|c|}
\hline & & & $\mathbf{P t}, n$ & Events, $n$ & Log-rank $P$ & HR (95\% Cl) \\
\hline Clinical characteristics & $\begin{array}{l}\text { Age, year } \\
\text { Gender } \\
\text { Ethnicity } \\
\text { BMI } \\
\text { Smoking status } \\
\text { Drinking status } \\
\text { Cirrhosis }\end{array}$ & $\begin{array}{l}\leq 60 \\
>60 \\
\text { Male } \\
\text { Female } \\
\text { Han } \\
\text { Minority } \\
\leq 25 \\
>25 \\
\text { None } \\
\text { Ever } \\
\text { None } \\
\text { Ever } \\
\text { Absent } \\
\text { Present }\end{array}$ & $\begin{array}{l}141 \\
16 \\
131 \\
26 \\
83 \\
74 \\
116 \\
41 \\
111 \\
46 \\
110 \\
47 \\
37 \\
120\end{array}$ & $\begin{array}{l}38 \\
4 \\
34 \\
8 \\
23 \\
19 \\
34 \\
8 \\
29 \\
13 \\
32 \\
10 \\
7 \\
35\end{array}$ & $\begin{array}{l}0.865 \\
0.674 \\
0.801 \\
0.233 \\
0.993 \\
0.237 \\
0.204\end{array}$ & $\begin{array}{l}\mathrm{I} \\
0.916(0.327-2.566) \\
\mathrm{I} \\
\mathrm{I} . \mathrm{I} 77(0.545-2.545) \\
\mathrm{I} \\
0.926(0.504-1.700) \\
\mathrm{I} \\
0.63 \mathrm{I}(0.292-1.364) \\
\mathrm{I} \\
\mathrm{I} .003(0.52 \mathrm{I}-\mathrm{I} .929) \\
\mathrm{I} \\
0.657(0.323-1.336) \\
\mathrm{I} \\
\mathrm{I} .673(0.743-3.769)\end{array}$ \\
\hline & $\begin{array}{l}\text { Splenomegaly } \\
\text { Ascites } \\
\text { Positions } \\
\text { Tumor size, cm } \\
\text { Peritumoral enhancement } \\
\text { Necrosis } \\
\text { RVI } \\
\text { Tumor margin } \\
\text { Radiological capsule } \\
\text { Esophageal, gastric varices }\end{array}$ & $\begin{array}{l}\text { Absent } \\
\text { Present } \\
\text { Absent } \\
\text { Present } \\
\text { Left lobe } \\
\text { Right lobe } \\
\text { Both } \\
<10 \\
\geq 10 \\
\text { Absent } \\
\text { Present } \\
\text { Absent } \\
\text { Present } \\
\text { Absent } \\
\text { Present } \\
\text { Smooth } \\
\text { Non-smooth } \\
\text { Complete } \\
\text { Incomplete } \\
\text { Absent } \\
\text { Absent } \\
\text { Present }\end{array}$ & $\begin{array}{l}69 \\
88 \\
146 \\
11 \\
38 \\
110 \\
9 \\
142 \\
15 \\
142 \\
15 \\
63 \\
94 \\
121 \\
36 \\
99 \\
58 \\
75 \\
50 \\
32 \\
141 \\
16\end{array}$ & $\begin{array}{l}17 \\
25 \\
38 \\
4 \\
7 \\
33 \\
2 \\
35 \\
7 \\
38 \\
4 \\
16 \\
26 \\
26 \\
16 \\
17 \\
25 \\
17 \\
15 \\
10 \\
35 \\
7\end{array}$ & $\begin{array}{l}0.583 \\
0.396 \\
0.421 \\
0.022 \\
0.867 \\
0.728 \\
0.002 \\
0.000 \\
0.538 \\
0.104\end{array}$ & $\begin{array}{l}\mathrm{I} \\
\mathrm{I} . \mathrm{I} 86(0.640-2.196) \\
\mathrm{I} \\
\mathrm{I} .550(0.552-4.346) \\
\mathrm{I} \\
\mathrm{I} .693(0.749-3.829) \\
\mathrm{I} .306(0.27 \mathrm{I}-6.29 \mathrm{I}) \\
\mathrm{I} \\
2.484(\mathrm{I} .10 \mathrm{I}-5.605) \\
\mathrm{I} \\
0.9 \mathrm{I} 7(0.327-2.569) \\
\mathrm{I} \\
\mathrm{I} . \mathrm{I} 16(0.598-2.080) \\
\mathrm{I} \\
2.527(\mathrm{I} .353-4.722) \\
\mathrm{I} \\
3.029(\mathrm{I} .63 \mathrm{I}-5.623) \\
\mathrm{I} \\
\mathrm{I} .390(0.694-2.783) \\
\mathrm{I} .44 \mathrm{I}(0.659-3.147) \\
\mathrm{I} \\
\mathrm{I} .925(0.854-4.340)\end{array}$ \\
\hline Pathological evidence & $\begin{array}{l}\text { Histological differentiation } \\
\text { Satellite node } \\
\text { MVI } \\
\text { Liver capsular invasion }\end{array}$ & $\begin{array}{l}\text { Well } \\
\text { Moderate } \\
\text { Poor } \\
\text { Absent } \\
\text { Present } \\
\text { Absent } \\
\text { Present } \\
\text { Absent } \\
\text { Present }\end{array}$ & $\begin{array}{l}11 \\
75 \\
71 \\
143 \\
14 \\
102 \\
55 \\
81 \\
76\end{array}$ & $\begin{array}{l}2 \\
19 \\
21 \\
39 \\
3 \\
19 \\
23 \\
20 \\
22\end{array}$ & $\begin{array}{l}0.703 \\
0.727 \\
0.002 \\
0.949\end{array}$ & $\begin{array}{l}\mathrm{I} \\
\mathrm{I} .528(0.356-6.562) \\
\mathrm{I} .763(0.4 \mathrm{I}-7.5 \mathrm{I}) \\
\mathrm{I} \\
0.8 \mathrm{I} 3(0.25 \mathrm{I}-2.633) \\
\mathrm{I} \\
2.724(\mathrm{I} .480-5.0 \mathrm{I}) \\
\mathrm{I} \\
0.98 \mathrm{I}(0.535-\mathrm{I} .797)\end{array}$ \\
\hline Serum parameters & $\begin{array}{l}\text { AFP, } n g / m L \\
\text { A/G }\end{array}$ & $\begin{array}{l}<400 \\
\geq 400 \\
\leq 2.5 \\
>2.5\end{array}$ & $\begin{array}{l}97 \\
60 \\
148 \\
9\end{array}$ & $\begin{array}{l}22 \\
20 \\
38 \\
4\end{array}$ & $\begin{array}{l}0.098 \\
0.117\end{array}$ & $\begin{array}{l}\text { I } \\
\text { I.650( }(0.900-3.025) \\
\text { I } \\
2.214(0.788-6.221)\end{array}$ \\
\hline
\end{tabular}

(Continued) 
Table 2 (Continued).

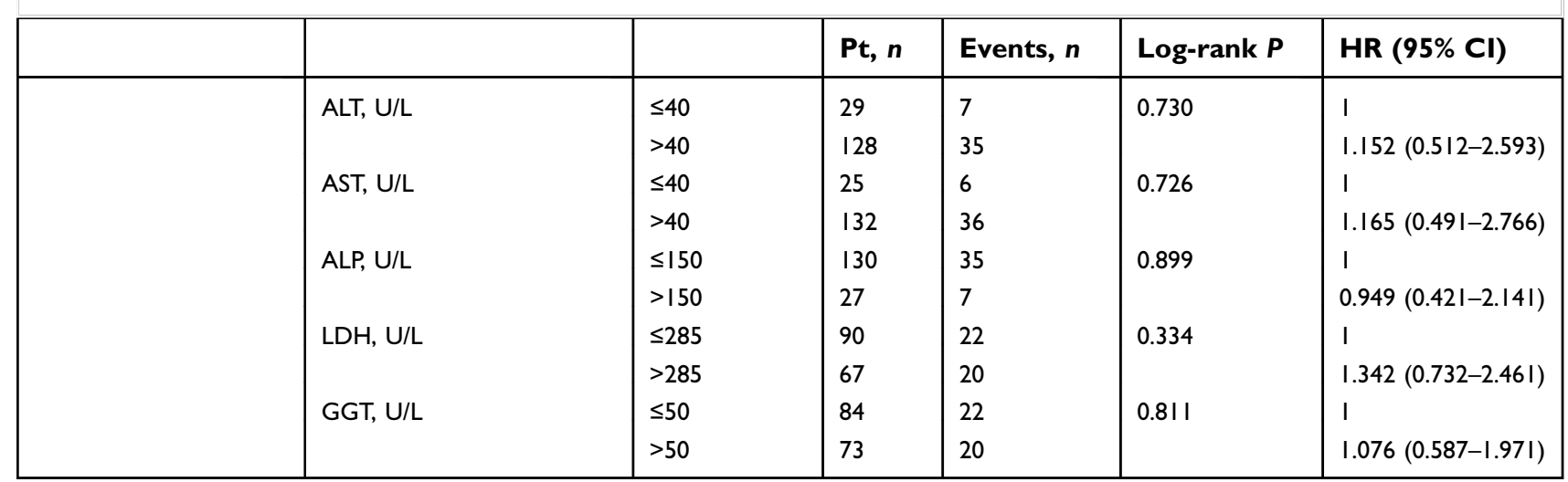

Abbreviations: CT, computed tomography; MVI, microvascular invasion; RVI, radiographic venous invasion; Pt, patient; AFP, alpha-fetoprotein; A/G, serum albumin to globulin; ALT, alanine aminotransferase; ALP, alkaline phosphatase; LDH, lactate dehydrogenase; GGT, $\gamma$-glutamyl transferase.

radiologic evidence of positive RVI, non-smooth tumor margin (not investigated previously), and larger tumor size were significantly associated with poor DFS. Nonsmooth tumor margin was an independent risk factor for recurrence and metastasis. The nomogram performed well in predicting the DFS of patients with HBVrelated solitary $\mathrm{HCC}$, and its prediction was supported by the calibration curve and bootstrapping validation.

Our results regarding lack of association between the prognostic risk factors and OS were not consistent with a previous study, which found radiologic evidence that positive RVI was associated with poor OS. ${ }^{25}$ This discrepancy may be due to differences in the inclusion criteria of the studies, that in the present study in the overall cohort there were only 10 cases of death (since the tumor was radically resected), and the follow-up time was not sufficient. A follow-up study will be necessary to confirm an association between CT features and $\mathrm{OS}$ in HBV-related $\mathrm{HCC}$ after curative resection.

In the present study, the univariate analysis indicated that liver capsular invasion was significantly associated with poor OS. This result was consistent with previous reports. $^{43,44}$ Liver capsular invasion was the natural biological behavior of the tumor. However, the multivariate analysis showed that liver capsular invasion was not significantly associated with OS. This result needs to be further validated, because there were only 10 deaths in the overall cohort.

In the present study, radiologic evidence of positive RVI, non-smooth tumor margin, and larger tumor size were significantly associated with poor DFS. In other studies, investigations have shown that non-smooth tumor margin ${ }^{29}$ and $\mathrm{RVI}^{25}$ were associated with MVI. MVI has been validated as a powerful and independent predictor of recurrence after surgical treatment. ${ }^{45-47}$

Interestingly, in a subgroup analysis of negative MVI in the present study, a positive RVI and nonsmooth tumor margin remained significantly associated with worse DFS, whereas MVI positivity was not. A possible reason is that imaging features reveal gene expression patterns of the tumor, ${ }^{20-22}$ but not MVI itself, and may capture more phenotypes of the tumor. Other possible reasons are that the sample size of positive MVI in the present study was only 55 patients, and these cases had undergone routine antiviral therapy and chemotherapy after curative resection in our hospital. Furthermore, a non-smooth tumor margin as a significant predictor of poor DFS may be related to tumor biological aggressiveness, and multicentric HCC should be considered. One of our previous studies showed that nodular borders of nonsmooth tumors are rich in pathological vessels, ${ }^{48}$ which may be one of the causes of recurrence and metastasis.

Numerous studies have shown that tumor size is a predictor of poor prognosis in $\mathrm{HCC}^{25,47,49,50}$ Similarly, we found in the present study that the HR of tumors $\geq 10 \mathrm{~cm}$ for radiologic evidence of poor DFS was significantly higher than the corresponding HR of tumors $<10 \mathrm{~cm}$.

In this retrospective study, we investigated whether histological MVI is an independent predictor for poor prognosis in HBV-related HCC patients. The results 


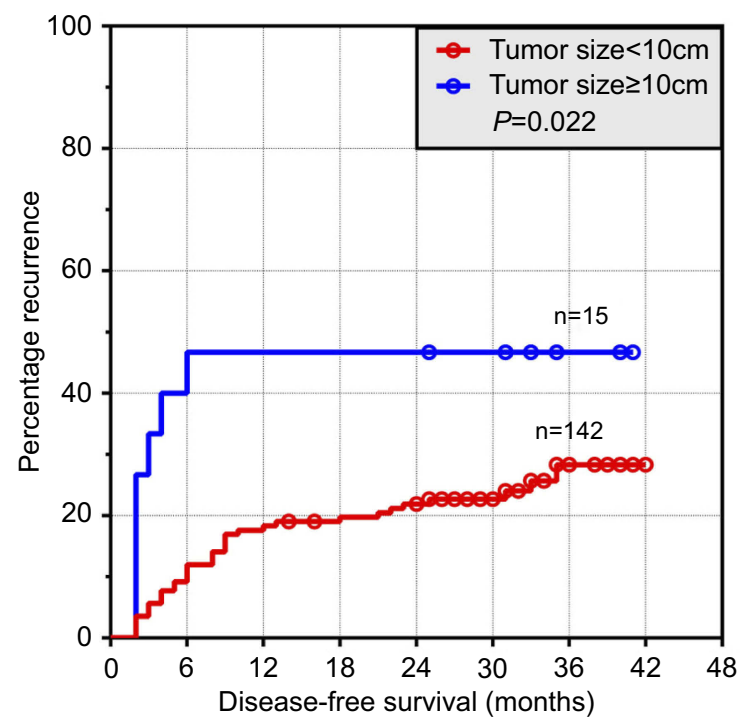

A

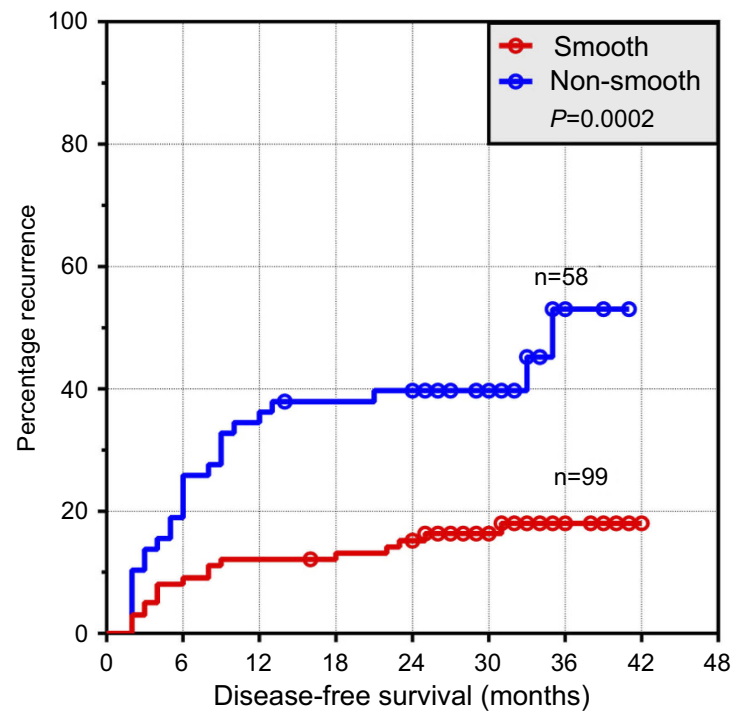

C

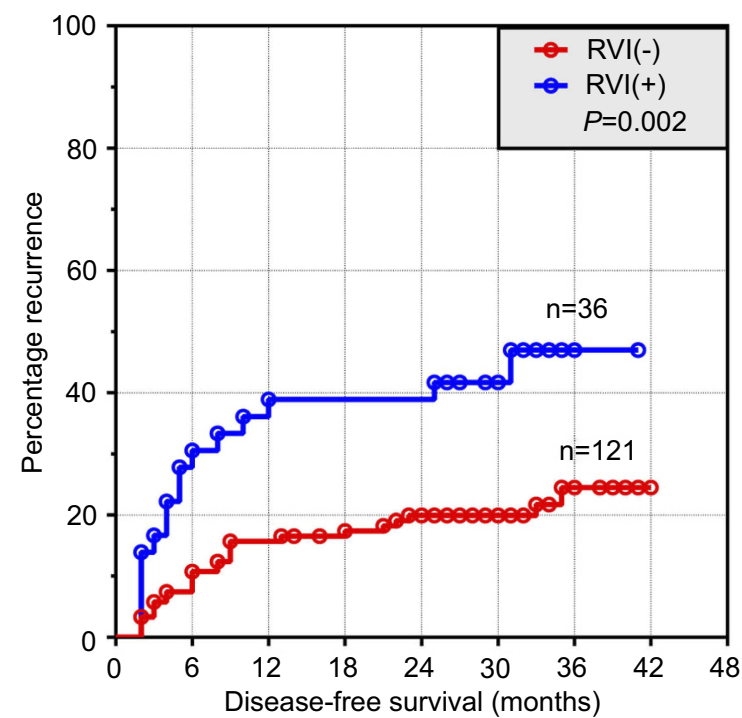

B

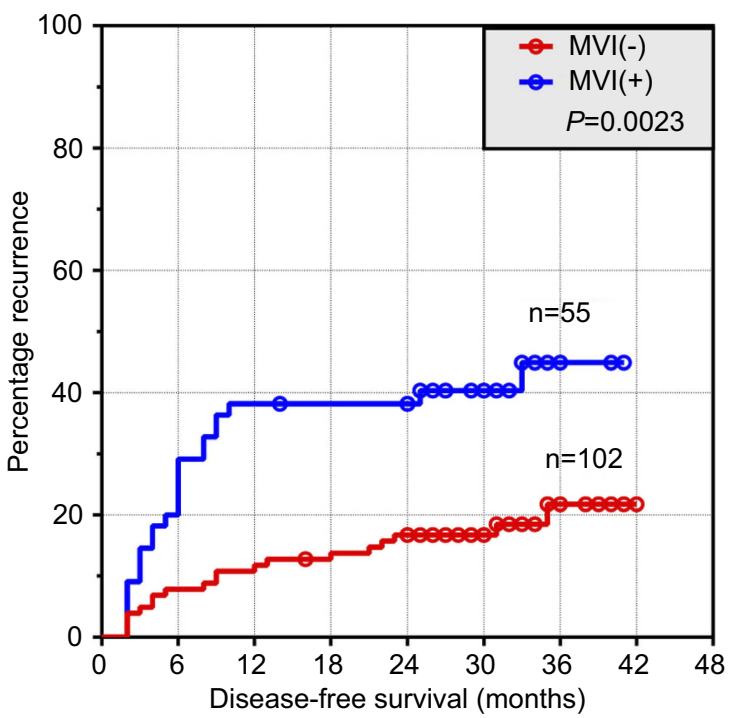

D

Figure 3 DFS curves of 157 patients with HBV-related HCC who underwent curative resection.

Abbreviations: HCC, hepatocellular carcinoma; MVI, microvascular invasion; RVI, radiographic venous invasion.

showed that although these patients with histological MVI had been given regular antiviral therapy and chemotherapy, histological MVI remained associated with worse DFS. Thus, the poor outcome predicted by histological MVI should be kept in mind. Poor differentiation is commonly considered to suggest a high risk for poor survival. ${ }^{51}$ However, our data indicated no statistical association between pathology grade and DFS. No other imaging traits, pathology, or clinical features were useful in significantly predicting DFS.

This study was limited by a small sample size, and a future study with a larger patient population is essential to validate the result. In addition, this was a singlecenter study, the retrospective cohort and imaging methods varied, and selection bias may exist. A third potential limitation is the use of $\mathrm{CT}$, which is 
Table 3 Multivariate analysis of preoperative factors associated with disease-free survival

\begin{tabular}{|c|c|c|c|c|}
\hline & & & Adjusted Log-rank $P$ & Adjusted HR (95\% Cl) \\
\hline CT signatures & $\begin{array}{l}\text { Cirrhosis } \\
\text { Splenomegaly } \\
\text { Ascites } \\
\text { Positions } \\
\text { Tumor size, cm } \\
\text { Peritumoral enhancement } \\
\text { Necrosis } \\
\text { RVI } \\
\text { Tumor margin } \\
\text { Radiological capsule } \\
\text { Esophageal, gastric varices }\end{array}$ & 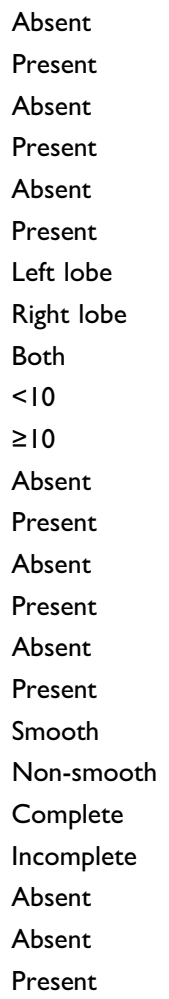 & $\begin{array}{l}0.114 \\
0.900 \\
0.073 \\
0.713 \\
0.020 \\
0.852 \\
0.160 \\
0.021 \\
0.036 \\
0.980 \\
0.067\end{array}$ & $\begin{array}{l}\mathrm{I} \\
2.347(0.8 \mathrm{I}-6.769) \\
\mathrm{I} \\
0.953(0.448-2.027) \\
\mathrm{I} \\
3.436(0.890-13.264) \\
\mathrm{I} \\
\mathrm{I} .438(0.513-4.034) \\
0.908(0.158-5.217) \\
\mathrm{I} \\
3.875(1.242-12.089) \\
\mathrm{I} \\
\mathrm{I} .116(0.352-3.539) \\
\mathrm{I} \\
0.54 \mathrm{I}(0.230-1.274) \\
\mathrm{I} \\
2.589(\mathrm{I} .157-5.795) \\
\mathrm{I} \\
2.296(1.054-5.003) \\
\mathrm{I} \\
\mathrm{I} .070(0.458-2.497) \\
0.977(0.391-2.44 \mathrm{I}) \\
\mathrm{I} \\
2.596(0.937-7.193)\end{array}$ \\
\hline Pathological evidence & $\begin{array}{l}\text { Histological differentiation } \\
\text { Satellite node } \\
\mathrm{MVI}^{\dagger} \\
\text { Liver capsular invasion }\end{array}$ & $\begin{array}{l}\text { Well } \\
\text { Moderate } \\
\text { Poor } \\
\text { Absent } \\
\text { Present } \\
\text { Absent } \\
\text { Present } \\
\text { Absent } \\
\text { Present }\end{array}$ & $\begin{array}{l}0.955 \\
0.353 \\
0.018 \\
0.184\end{array}$ & $\begin{array}{l}\text { I } \\
\text { I.263 }(0.24 I-6.607) \\
\text { I.284 }(0.257-6.40 I) \\
I \\
0.5 I 0(0.123-2.115) \\
I \\
2.53 \mathrm{I}(1.169-5.48 \mathrm{I}) \\
\mathrm{I} \\
0.598(0.280-1.277)\end{array}$ \\
\hline Serum parameters & $\begin{array}{l}\text { AFP, ng/mL } \\
\text { A/G } \\
\text { ALT, U/L } \\
\text { AST, U/L } \\
\text { ALP, U/L } \\
\text { LDH, U/L } \\
\text { GGT, U/L }\end{array}$ & $\begin{array}{l}<400 \\
\geq 400 \\
\leq 2.5 \\
>2.5 \\
\leq 40 \\
>40 \\
\leq 40 \\
>40 \\
\leq 150 \\
>150 \\
\leq 285 \\
>285 \\
\leq 50 \\
>50\end{array}$ & $\begin{array}{l}0.620 \\
0.198 \\
0.240 \\
0.411 \\
0.594 \\
0.348 \\
0.428\end{array}$ & $\begin{array}{l}\mathrm{I} \\
\mathrm{I} .2 \mathrm{I} 3(0.565-2.606) \\
\mathrm{I} \\
2.264(0.652-7.857) \\
\mathrm{I} \\
2.192(0.592-8.120) \\
\mathrm{I} \\
0.580(0.158-2.129) \\
\mathrm{I} \\
0.774(0.302-1.984) \\
\mathrm{I} \\
\mathrm{I} .438(0.673-3.070) \\
\mathrm{I} \\
0.733(0.34 \mathrm{I}-\mathrm{I} .580)\end{array}$ \\
\hline
\end{tabular}

Note: ${ }^{\dagger} \mathrm{RVI}$ and $\mathrm{MVI}$ were analyzed separately because of collinearity between RVI and MVI.

Abbreviations: CT, computed tomography; MVI, microvascular invasion; RVI, radiographic venous invasion; AFP, alpha-fetoprotein; A/G, serum albumin to globulin; ALT, alanine aminotransferase; ALP, alkaline phosphatase; LDH, lactate dehydrogenase; GGT, $\gamma$-glutamyl transferase. 


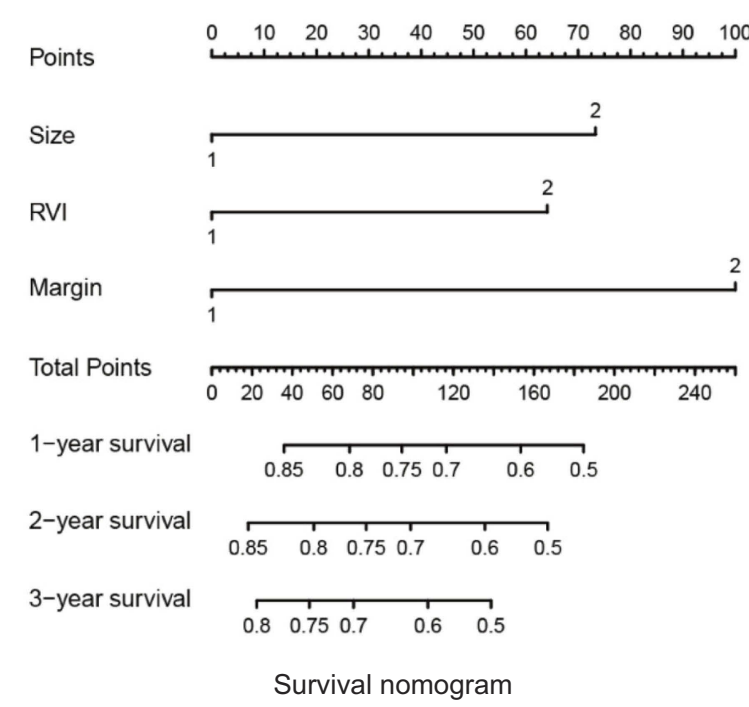

A

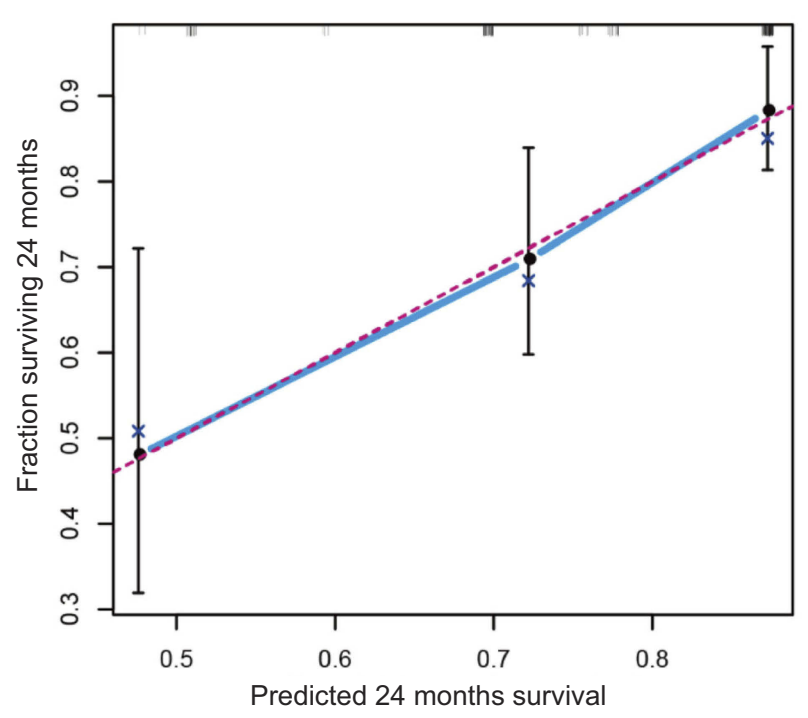

C

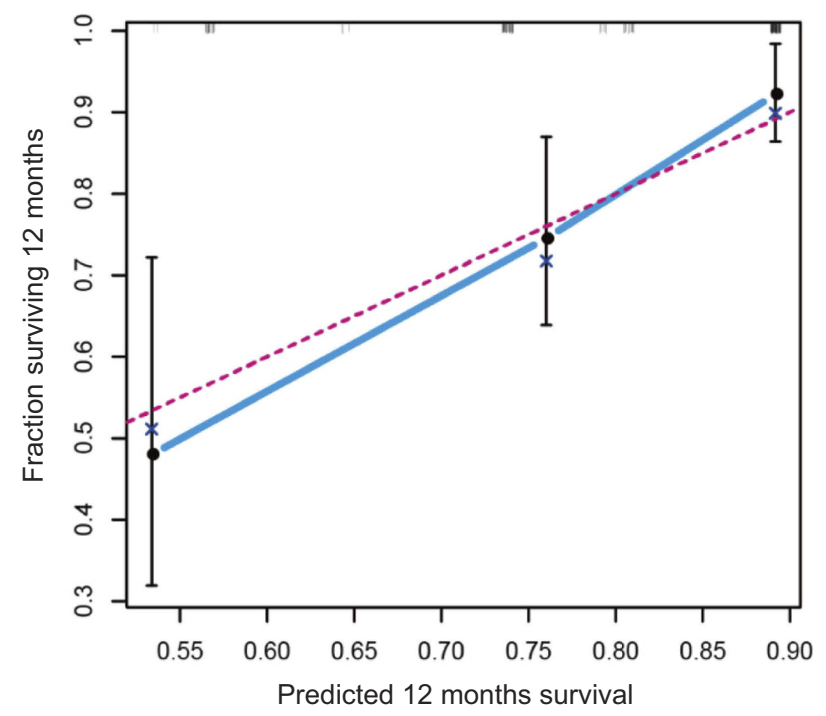

B

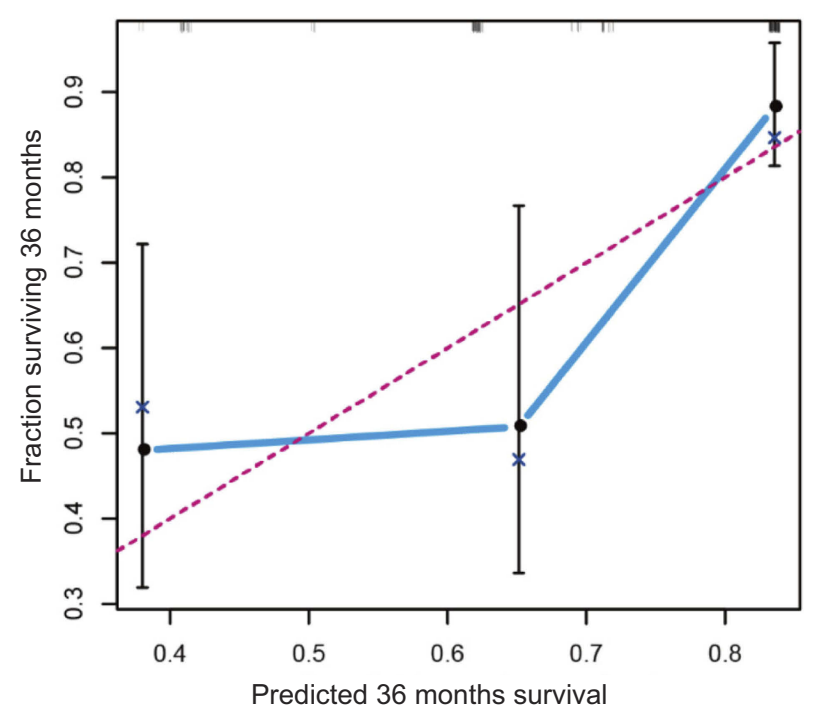

D

Figure 4 Prognostic nomogram of preoperative CT for DFS in patients with HBV-related HCC after curative resection. (A) DFS nomogram. To use the nomogram, the value of an individual patient is located on each variable axis, and a line is drawn upward to determine the number of points received for each variable value. The sum of these numbers is located on the total point axis, and a line is drawn downward to the survival axes to determine the likelihood of I-, 2-, and 3-year DFS. (B-D) The calibration curve of DFS at (B) I-, (C) 2-, and (D) 3-years in the validation cohort. Nomogram-predicted probability of DFS is plotted on the $x$-axis, actual DFS is plotted on the $y$-axis. Size is the maximal diameter of the largest cross section; margin is the radiologic evidence of tumor margin.

Abbreviations: CT, computed tomography; HCC, hepatocellular carcinoma; RVI, radiographic venous invasion.

commonly used for HCC evaluation, but may be inferior to MRI. The fourth limitation is that MVI can predict postoperative $\mathrm{HCC}$ recurrence and there is a positive correlation between tumor margin and postoperative $\mathrm{HCC}$ recurrence, but it does not necessarily means tumor margin can predict MVI. The further study is necessary.

\section{Conclusion}

Noninvasive preoperative CT imaging characteristics may be useful to prognosticate DFS. The nomogram was developed for predicting individual DFS in patients with HBV-related solitary HCC. Patients with HBV-related HCC with radiologic evidence of positive RVI, non-smooth tumor margin, or tumor size $\geq 10 \mathrm{~cm}$ may require more aggressive treatment (such as 


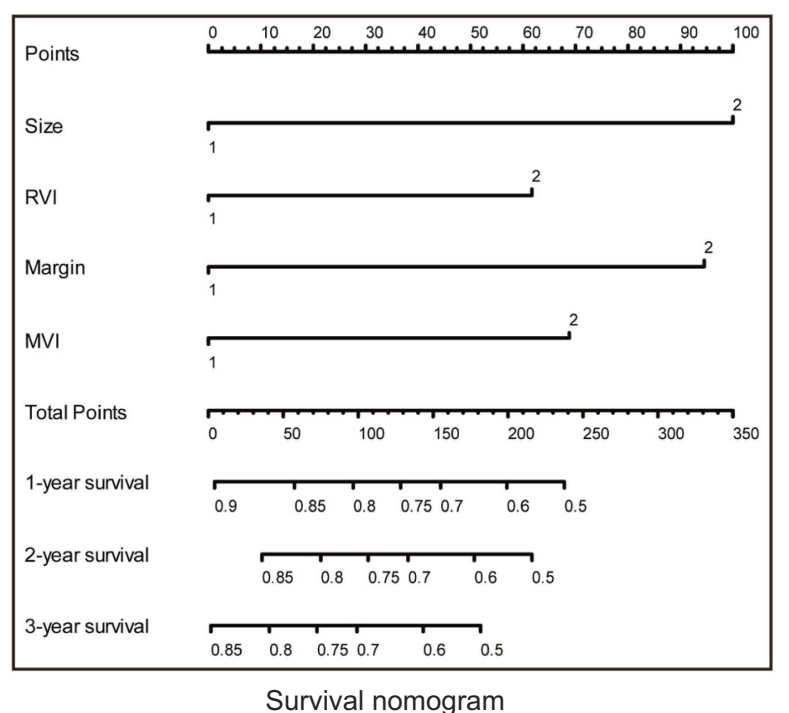

A

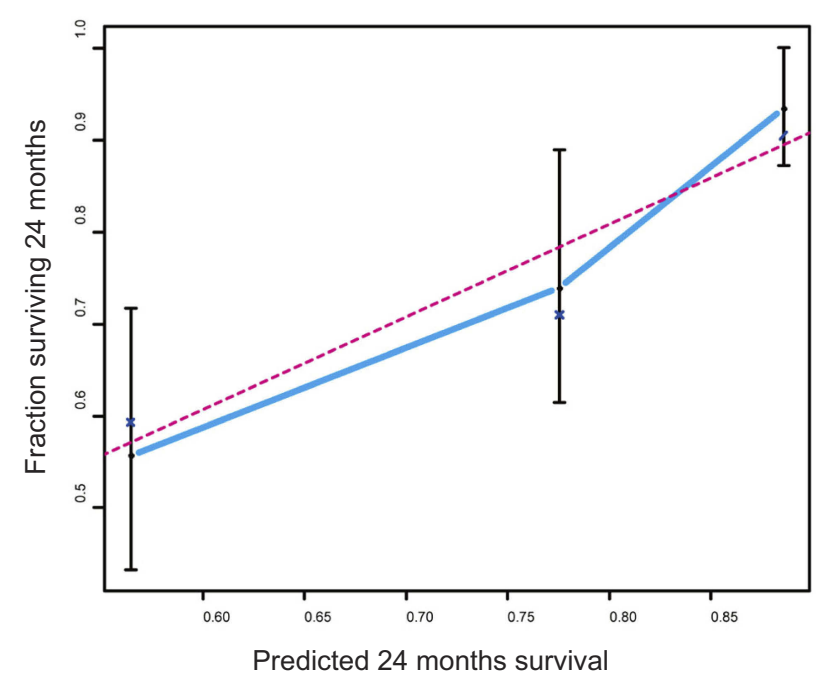

C

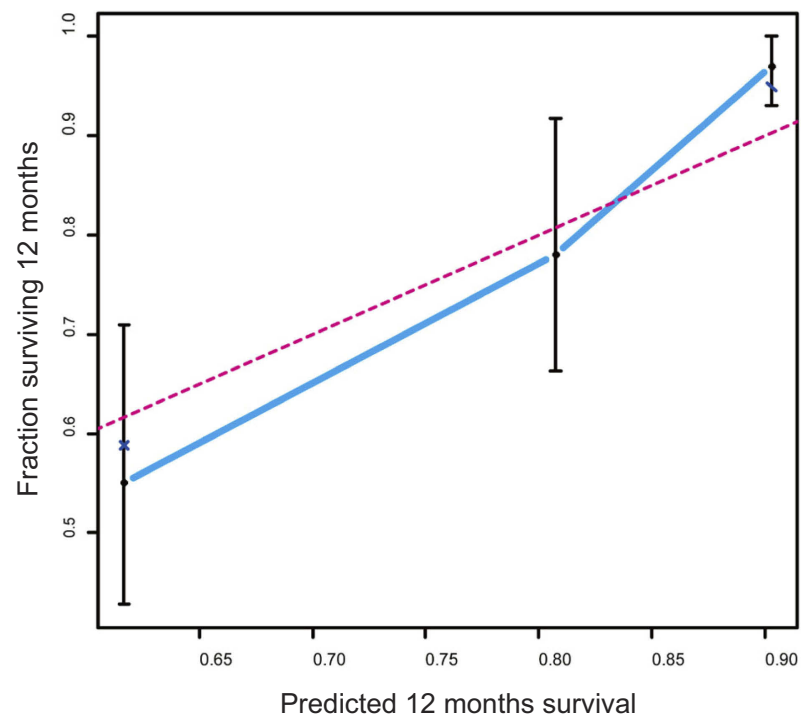

B

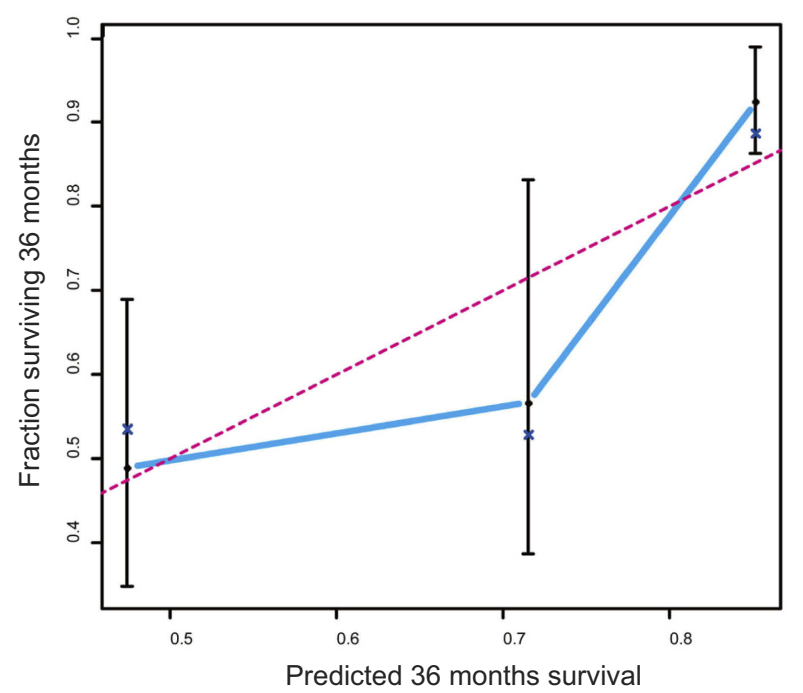

D

Figure 5 DFS nomogram for HBV-related HCC after curative resection. (A) Nomogram for predicting I-, 2-, and 3-year probability of DFS in patients with HBV-related $\mathrm{HCC}$ after curative resection. To estimate risk, points for each variable were calculated by drawing a straight line from patient's variable value to the axis labeled "Points"; all points were summed, and a line drawn from the total point axis to the 1-, 2-, and 3-year DFS. (B-D) The calibration curve of DFS at (B) I-, (C) 2-, and (D) 3-years in the validation cohort. Nomogram-predicted probability of DFS is plotted on the x-axis, actual DFS is plotted on the $y$-axis. Size is the maximal diameter of the largest cross section; margin is the radiologic evidencethe tumor margin.

Abbreviations: CT, computed tomography; HCC, hepatocellular carcinoma; MVI, microvascular invasion; RVI, radiographic venous invasion.

wide resection margins during curative resection) to reduce rates of recurrence and metastasis. However, our results still need further verification in multi-center with large sample size.

\section{Acknowledgments}

This work was supported by the Innovation Project of Guangxi Graduate Education (Grant No. YCBZ2017042), Guangxi Medical and Health Appropriate Technology research program (Grant No.
S201632), Guangxi Education Department research program (Grant No. KY2016YB082), Guangxi Science and Technology Department research program (Grant No. AB18126031), Guangxi Medical University research program (Grant No. GXMUYSF201401), and International Communication of Guangxi Medical University Graduate Education (2017), for which the authors are grateful. We are very grateful to the editor and reviewers. 


\section{Disclosure}

The authors report no conflicts of interest in this work.

\section{References}

1. Schweitzer A, Horn J, Mikolajczyk RT, Krause G, Ott JJ. Estimations of worldwide prevalence of chronic hepatitis $\mathrm{B}$ virus infection: a systematic review of data published between 1965 and 2013. Lancet 2015;386(10003):1546-1555. doi:10.1016/S0140-6736(15)61412-X

2. Torre LA, Bray F, Siegel RL, Ferlay J, Lortet-Tieulent J, Jemal A. Global cancer statistics, 2012. CA Cancer J Clin. 2015;65(2):87-108. doi:10.3322/caac. 21262

3. Zeng H, Zheng R, Guo Y, et al. Cancer survival in China, 2003-2005: a population-based study. Int $J$ Cancer. 2015;136(8):1921-1930. doi:10.1002/ijc.29227

4. El-Serag HB, Rudolph KL. Hepatocellular carcinoma: epidemiology and molecular carcinogenesis. Gastroenterology. 2007;132 (7):2557-2576. doi:10.1053/j.gastro.2007.04.061

5. McGlynn KA, Petrick JL, London WT. Global epidemiology of hepatocellular carcinoma: an emphasis on demographic and regional variability. Clin Liver Dis. 2015;19(2):223-238. doi:10.1016/j. cld.2015.01.001

6. Zhou M, Wang H, Zhu J, et al. Cause-specific mortality for 240 causes in China during 1990-2013: a systematic subnational analysis for the Global Burden of Disease Study 2013. Lancet. 2016;387 (10015):251-272. doi:10.1016/S0140-6736(15)00551-6

7. Qi L-N, Bai T, Chen Z-S, et al. The p53 mutation spectrum in hepatocellular carcinoma from Guangxi, China: role of chronic hepatitis B virus infection and aflatoxin B1 exposure. Liver Int. 2015;35 (3):999-1009. doi:10.1111/liv.12460

8. Xu L, Qian G, Tang L, Su J, Wang J-S. Genetic variations of hepatitis $\mathrm{B}$ virus and serum aflatoxin-lysine adduct on high risk of hepatocellular carcinoma in Southern Guangxi, China. J Hepatol. 2010;53 (4):671-676. doi:10.1016/j.jhep.2010.04.032

9. Forner A, Llovet JM, Bruix J. Hepatocellular carcinoma. Lancet. 2012;379(9822):1245-1255. doi:10.1016/S0140-6736(11)61347-0

10. Zimmerman MA, Ghobrial RM, Tong MJ, et al. Recurrence of hepatocellular carcinoma following liver transplantation: a review of preoperative and postoperative prognostic indicators. Arch Surg. 2008;143(2):182-188, discussion 188. doi:10.1001/ archsurg.2007.39

11. Shah SA, Cleary SP, Wei AC, et al. Recurrence after liver resection for hepatocellular carcinoma: risk factors, treatment, and outcomes. Surgery. 2007;141(3):330-339. doi:10.1016/j. surg.2006.06.028

12. Shimozawa N, Hanazaki K. Longterm prognosis after hepatic resection for small hepatocellular carcinoma. J Am Coll Surg. 2004;198 (3):356-365. doi:10.1016/j.jamcollsurg.2003.10.017

13. Poon RT, Fan ST, Lo CM, Liu CL, Wong J. Long-term survival and pattern of recurrence after resection of small hepatocellular carcinoma in patients with preserved liver function: implications for a strategy of salvage transplantation. Ann Surg. 2002;235 (3):373-382.

14. Grazi GL, Ercolani G, Pierangeli F, et al. Improved results of liver resection for hepatocellular carcinoma on cirrhosis give the procedure added value. Ann Surg. 2001;234(1):71-78.

15. Villa E, Critelli R, Lei B, et al. Neoangiogenesis-related genes are hallmarks of fast-growing hepatocellular carcinomas and worst survival. Results from a prospective study. Gut. 2016;65(5):861-869. doi:10.1136/gutjnl-2014-308483

16. Choi SJ, Kim J, Seo J, Kim HS, Lee J-M, Park H. Parametric response mapping of dynamic $\mathrm{CT}$ for predicting intrahepatic recurrence of hepatocellular carcinoma after conventional transcatheter arterial chemoembolization. Eur Radiol. 2016;26(1):225-234. doi:10.1007/s00330-015-3825-x
17. Kim SM, Leem S-H, Chu I-S, et al. Sixty-five gene-based risk score classifier predicts overall survival in hepatocellular carcinoma. Hepatology. 2012;55(5):1443-1452. doi:10.1002/hep.24813

18. Hoshida Y, Villanueva A, Kobayashi M, et al. Gene expression in fixed tissues and outcome in hepatocellular carcinoma. $N$ Engl J Med. 2008;359(19):1995-2004. doi:10.1056/NEJMoa0804525

19. Iizuka N, Oka M, Yamada-Okabe H, et al. Oligonucleotide microarray for prediction of early intrahepatic recurrence of hepatocellular carcinoma after curative resection. Lancet. 2003;361(9361):923-929. doi:10.1016/S0140-6736(03)12775-4

20. Segal E, Friedman N, Kaminski N, Regev A, Koller D. From signatures to models: understanding cancer using microarrays. Nat Genet. 2005;37(Suppl):S38-S45. doi:10.1038/ng1561

21. Segal E, Sirlin CB, Ooi C, et al. Decoding global gene expression programs in liver cancer by noninvasive imaging. Nat Biotechnol. 2007;25(6):675-680. doi:10.1038/nbt1306

22. Kuo MD, Yamamoto S. Next generation radiologic-pathologic correlation in oncology: Rad-Path 2.0. AJR Am J Roentgenol. 2011;197 (4):990-997. doi:10.2214/AJR.11.7163

23. Huang Y-Q, Liang C-H, He L, et al. Development and validation of a radiomics nomogram for preoperative prediction of lymph node metastasis in colorectal cancer. J Clin Oncol. 2016;34 (18):2157-2164. doi:10.1200/JCO.2015.65.9128

24. Zhou Y, He L, Huang Y, et al. CT-based radiomics signature: a potential biomarker for preoperative prediction of early recurrence in hepatocellular carcinoma. Abdom Radiol. 2017;42(6):1695-1704. doi:10.1007/s00261-017-1072-0

25. Banerjee S, Wang DS, Kim HJ, et al. A computed tomography radiogenomic biomarker predicts microvascular invasion and clinical outcomes in hepatocellular carcinoma. Hepatology. 2015;62 (3):792-800. doi:10.1002/hep.27877

26. Poon RT, Fan ST, Ng IO, Lo CM, Liu CL, Wong J. Different risk factors and prognosis for early and late intrahepatic recurrence after resection of hepatocellular carcinoma. Cancer. 2000;89 (3):500-507.

27. Clavien P-A, Lesurtel M, Bossuyt PM, Gores GJ, Langer B, Perrier A. Recommendations for liver transplantation for hepatocellular carcinoma: an international consensus conference report. Lancet Oncol. 2012;13(1):e11-e22. doi:10.1016/S1470-2045(11) 70175-9

28. Lim K-C, Chow PK, Allen JC, et al. Microvascular invasion is a better predictor of tumor recurrence and overall survival following surgical resection for hepatocellular carcinoma compared to the Milan criteria. Ann Surg. 2011;254(1):108-113. doi:10.1097/ SLA.0b013e31821ad884

29. Chou C-T, Chen R-C, Lin W-C, Ko C-J, Chen C-B, Chen Y-L. Prediction of microvascular invasion of hepatocellular carcinoma: preoperative $\mathrm{CT}$ and histopathologic correlation. AJR Am J Roentgenol. 2014;203(3):W253-W259. doi:10.2214 AJR.13.10595

30. Lee S, Kim SH, Lee JE, Sinn DH, Park CK. Preoperative gadoxetic acid-enhanced MRI for predicting microvascular invasion in patients with single hepatocellular carcinoma. $J$ Hepatol. 2017;67 (3):526-534. doi:10.1016/j.jhep.2017.04.024

31. Hu H, Zheng Q, Huang Y, et al. A non-smooth tumor margin on preoperative imaging assesses microvascular invasion of hepatocellular carcinoma: a systematic review and meta-analysis. Sci Rep. 2017;7(1):15375. doi:10.1038/s41598-017-15491-6

32. Wu T-H, Hatano E, Yamanaka K, et al. A non-smooth tumor margin on preoperative imaging predicts microvascular invasion of hepatocellular carcinoma. Surg Today. 2016;46(11):1275-1281. doi:10.1007/s00595-016-1320-x

33. Chou C-T, Chen R-C, Lee C-W, Ko C-J, Wu H-K, Chen Y-L. Prediction of microvascular invasion of hepatocellular carcinoma by pre-operative CT imaging. Br J Radiol. 2012;85(1014):778-783. doi:10.1259/bjr/65897774 
34. Zhang W, Lai S-L, Chen J, et al. Validated preoperative computed tomography risk estimation for postoperative hepatocellular carcinoma recurrence. World J Gastroenterol. 2017;23(35):6467-6473. doi:10.3748/wjg.v23.i35.6467

35. Mehta N, Heimbach J, Harnois DM, et al. Validation of a Risk Estimation of Tumor Recurrence After Transplant (RETREAT) score for hepatocellular carcinoma recurrence after liver transplant. JAMA Oncol. 2017;3(4):493-500. doi:10.1001/jamaoncol.2016.5116

36. Zhou L, Rui J-A, Zhou W-X, Wang S-B, Chen S-G, Qu Q. EdmondsonSteiner grade: a crucial predictor of recurrence and survival in hepatocellular carcinoma without microvascular invasio. Pathol Res Pract. 2017;213(7):824-830. doi:10.1016/j.prp.2017.03.002

37. Jin Y-J, Chung Y-H, Kim JA, et al. Factors predisposing metastatic tumor antigen 1 overexpression in hepatitis B virus associated hepatocellular carcinoma. Dig Dis Sci. 2012;57(11):2917-2923. doi:10.1007/s10620-012-2296-z

38. Lee EC, Kim SH, Park H, Lee SD, Lee S-A, Park S-J. Survival analysis after liver resection for hepatocellular carcinoma: a consecutive cohort of 1002 patients. J Gastroenterol Hepatol. 2017;32(5):1055-1063. doi:10.1111/jgh.13632

39. Bruix J, Sherman M; Practice Guidelines Committee AAftSoLD. Management of hepatocellular carcinoma. Hepatology. 2005;42 (5):1208-1236. doi:10.1002/hep.20933

40. Harbin WP, Robert NJ, Ferrucci JT Jr. Diagnosis of cirrhosis based on regional changes in hepatic morphology: a radiological and pathological analysis. Radiology. 1980;135(2):273-283. doi:10.1148/ radiology.135.2.7367613

41. Wang Y, Li J, Xia Y, et al. Prognostic nomogram for intrahepatic cholangiocarcinoma after partial hepatectomy. J Clin Oncol. 2013;31 (9):1188-1195. doi:10.1200/JCO.2012.41.5984

42. Harrell FE Jr, Lee KL, Mark DB. Multivariable prognostic models: issues in developing models, evaluating assumptions and adequacy, and measuring and reducing errors. Stat Med. 1996;15(4):361-387. doi:10.1002/ (SICI)1097-0258(19960229)15:4<361::AID-SIM168>3.0.CO;2-4

43. Wang J, Xu L-B, Liu C, Pang H-W, Chen Y-J, Ou Q-J. Prognostic factors and outcome of 438 Chinese patients with hepatocellular carcinoma underwent partial hepatectomy in a single center. World J Surg. 2010;34(10):2434-2441. doi:10.1007/s00268-010-0664-4
44. Ng IO, Lai EC, Fan ST, Ng MM, So MK. Prognostic significance of pathologic features of hepatocellular carcinoma. A multivariate analysis of 278 patients. Cancer. 1995;76(12):2443-2448.

45. Li T, Wang S-K, Zhou J, et al. Positive HBcAb is associated with higher risk of early recurrence and poorer survival after curative resection of HBV-related HCC. Liver Int. 2016;36(2):284-292. doi:10.1111/liv.12898

46. Li T, Qin L-X, Gong X, et al. Clinical characteristics, outcome, and risk factors for early and late intrahepatic recurrence of female patients after curative resection of hepatocellular carcinoma. Surgery. 2014;156(3):651-660. doi:10.1016/j. surg.2014.04.008

47. Chan AC, Fan ST, Poon RT, et al. Evaluation of the seventh edition of the American Joint Committee on Cancer tumour-node-metastasis (TNM) staging system for patients undergoing curative resection of hepatocellular carcinoma: implications for the development of a refined staging system. Hpb. 2013;15(6):439-448. doi:10.1111/ j.1477-2574.2012.00617.x

48. Zhang W, Liu L, Wang P, et al. Preoperative computed tomography and serum $\alpha$-fetoprotein to predict microvascular invasion in hepatocellular carcinoma. Medicine. 2018;97(27):e11402. doi:10.1097/ MD.0000000000011402

49. Lu X-Y, Xi T, Lau W-Y, et al. Pathobiological features of small hepatocellular carcinoma: correlation between tumor size and biological behavior. J Cancer Res Clin Oncol. 2011;137(4):567-575. doi:10.1007/s00432-010-0909-5

50. Ye J-Z, Chen J-Z, Li Z-H, et al. Efficacy of postoperative adjuvant transcatheter arterial chemoembolization in hepatocellular carcinoma patients with microvascular invasion. World J Gastroenterol. 2017;23 (41):7415-7424. doi:10.3748/wjg.v23.i41.7415

51. Martins-Filho SN, Paiva C, Azevedo RS, Alves VAF. Histological grading of hepatocellular carcinoma - a systematic review of literature. Front Med. 2017;4:193. doi:10.3389/fmed.2017.00129
OncoTargets and Therapy

\section{Publish your work in this journal}

OncoTargets and Therapy is an international, peer-reviewed, open access journal focusing on the pathological basis of all cancers, potential targets for therapy and treatment protocols employed to improve the management of cancer patients. The journal also focuses on the impact of management programs and new therapeutic agents and protocols on patient perspectives such as quality of life adherence and satisfaction. The manuscript management system is completely online and includes a very quick and fair peer-review system, which is all easy to use. Visit http://www.dovepress.com testimonials.php to read real quotes from published authors. 